\title{
Paratransit Operations in Roorkee
}

\author{
S. Praveen ${ }^{1}$ \\ ${ }^{1}$ CVR College of Engineering, Civil Engineering Department, Hyderabad, India \\ Email: samarthipraveen@gmail.com
}

\begin{abstract}
Rapid increase of urban population, per capita income, along with inadequate existing transport infrastructure has stimulated the usage of paratransit. The paratransit consist of a shared taxi or small bus that will run along more or less defined route, they are meant to stop in order to pick up the passengers or discharge the passengers to their destinations upon their request. Paratransit systems play a significant role in the urban transport sectors of developing countries. In Many cities more than half of the total public transport demand is met by them. They serve as a cheap and convenient public transport mode.

Paratransit services provide considerable degree of flexibility to the passengers. They offer flexible on-demand door-to-door service from any origin to any destination in a service area. Paratransit services are operated by public transit agencies, community groups etc.

Samples were collected in Roorkee city, detailed analysis and results based on road user's preferences were presented.
\end{abstract}

Index Terms- Mode, House hold Income, urban population and transport infrastructure

\section{INTRODUCTION}

Over the last three decades the word "paratransit" has migrated and taken to separate broad sets of meaning and application. The informal public transport modes or "paratransit" in developing countries encompass a variety of transport modes and service facilities falling in between the conventional transport services, fixed route, scheduled bus, urban rail and private auto mobiles. The concept of paratransit, however differs in the context of developed and developing countries. In developed countries, paratransit is often used for demand responsive systems such as shared-ride taxis, dial-a-ride and subscription buses. In the context of developing countries, the lower standard of living, high population density, availability of cheap labour force etc., have together provided a bewildering array of transport modes bridging the gap between public bus and private auto mobiles.

\section{A. Paratransit}

Paratransit is an alternative mode of flexible passenger transportation that does not allow fixed routes (or) schedules. Typically mini-buses are used to provide para transit service, but also share taxis and Jitneys are important providers. Paratransit provides service for people with disabilities and elder to reach their destinations based on their convenience.

\section{Classification of Paratransit:}

Paratransit modes are regarded as an important component of urban transport in the cities of developing countries due to its distinguishing characteristics, like low carrying capacity, low speed, low energy requirements, more dependable and small area of coverage. Generally, Paratransit system can be broadly classified into two types; non-motorized and motorised. Both types are again sub-classified into 3 groups based on their seating capacity. They are individual type (seating capacity less than 4), shared type (seating capacity of 5-10) and collective type (seating capacity of 11-20).The non-motorized paratransit includes animal powered and human powered types. The examples of animal powered paratransit are tonga in India and Pakistan, calesa in Philippines, dokar or delman in Indonesia.

TABLE I. TABLE I

TABLE II. PARATRANSIT SYSTEMS IN THE WORLD

\begin{tabular}{|c|c|c|}
\hline S. no & Country & Paratransit \\
\hline 1 & Thailand & Tuk-Tuk \\
\hline 2 & Dakar \& Senegal & Mini buses \\
\hline 3 & $\begin{array}{c}\text { Uganda, Kenya \& } \\
\text { Nairobi }\end{array}$ & Matatu \\
\hline 4 & Indonesia & Angkots \\
\hline
\end{tabular}

Need of Study

Paratransit is the main mode for public transport for short distances i.e., from $2 \mathrm{~km}$ to $10 \mathrm{kms}$ distance. Most of the people choose it as a primary mode of transport, to facilitate their movement in the city without causing any problem to other mode of transport. Prevailing on the road network of the city, proper planning and management of paratransit is required. To carry out such type of planning activity, it is necessary to enhance the characteristics of paratransit operations in the city of Roorkee.

\section{APPROACH AND METHODOLOGY}

\section{A. APPROCH}

To evaluate and judge the characteristics of paratransit mode in the city of Roorkee, a detail questionnaire which consist of questions related to the user and driver characteristics. The outcome of these 
questions is used to generate the data for the evaluation of the paratransit characteristics.

\section{B. METHODOLOGY}

The methodology adopted for the present study is based on the flow chart given in figure 1.

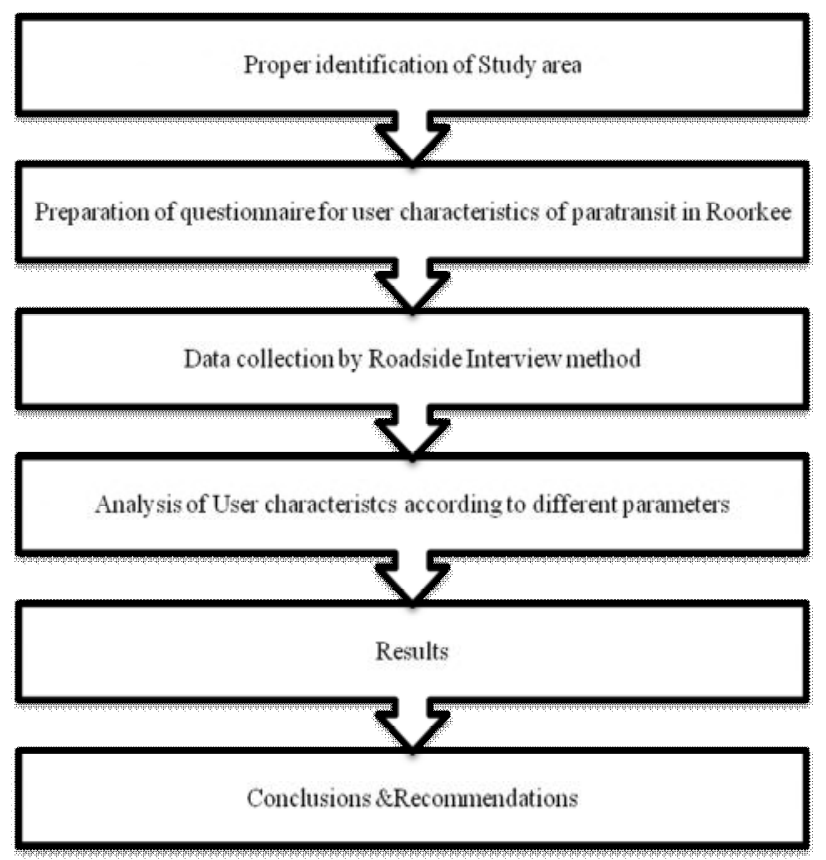

Figure 1. Flow chart showing the methodology

\section{STUDY AREA}

\section{A. Data Recording and Processing}

Data has been collected for various characteristics of users and drivers. Proper identification of location is very important for carrying out field study for data collection. Data Collection has to be made from location where adequate numbers of paratransits are available. Data collection was done by road side interview method. Data was collected at 3 locations namely SDM Chourah Road ways Junction and Malakpuri chungi. Survey forms were filled according to the information

\section{TABLE II}

TABLE III. SAMPLE DATA COLLECTED AT DIFFERENT LOCATIONS

\begin{tabular}{|c|c|c|c|}
\hline S. no & City & Location & $\begin{array}{c}\text { No of } \\
\text { Samples }\end{array}$ \\
\hline 1 & ROORKEE & $\begin{array}{c}\text { SDM } \\
\text { CHOURAHA }\end{array}$ & 35 \\
\hline 2 & ROORKEE & ROAD WAY & 35 \\
\hline 3 & ROORKEE & $\begin{array}{c}\text { MALAKPURI } \\
\text { CHUNGI }\end{array}$ & 30 \\
\hline
\end{tabular}

given by both users and drivers. 100 samples were taken for this survey. From the above mentioned locations information was taken from both driver and user regarding various characteristics, the number of samples collected at each location is presented in table2.

\section{SDM CHOURAHA}

1. The following figure 2 indicates that, $40 \%$ of the commuters using paratransit are having self contained flat and $60 \%$ of commuters has rental house.

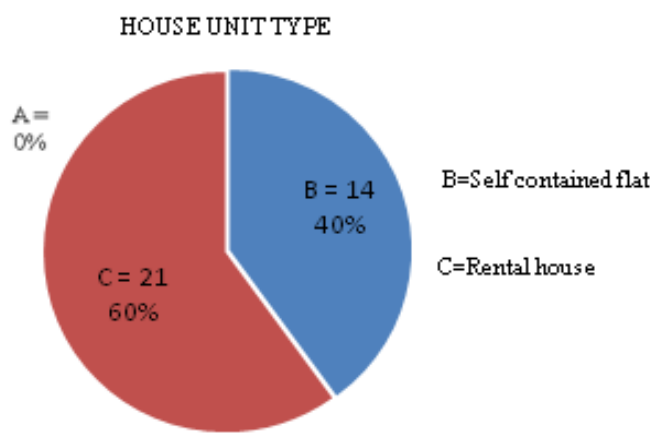

Figure2. Dis trbution of res ponses w.r.t house unitype

House Unit Type:

A: Luxury; B: self contained flat; C: Rental House

2. From the figure $3,37 \%$ of commuters using paratransit are having monthly income group between Rs.3000 to Rs.5000, 34\% of commuters are of income group between Rs.5000 to Rs. 10000 and $29 \%$ of commuters are of income group greater than Rs.10000.

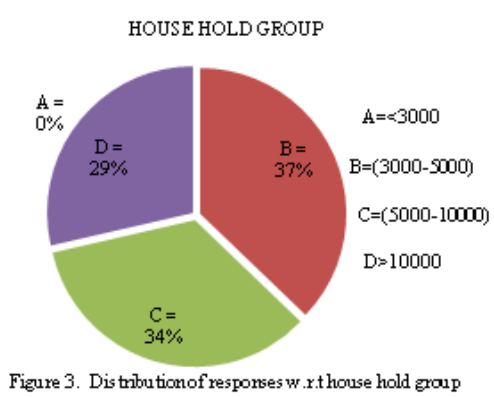

3. From the figure $4,11 \%$ of the commuters using paratransit are of students, $37 \%$ of commuters are industrial workers, $46 \%$ of commuters are businessmen and $6 \%$ of the commuters are others. OCCUPATION

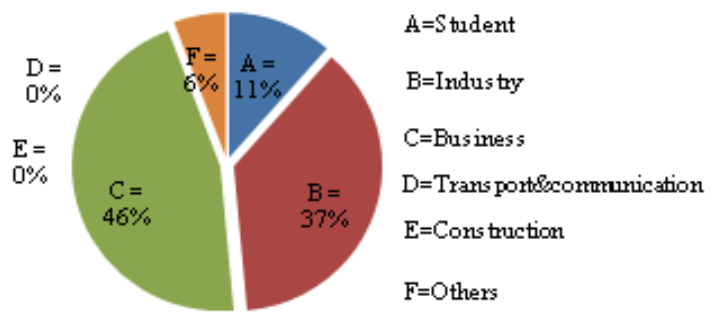

Figure 4. Dis tribution of resporses w.r.toccupation 
4. From the figure 5, $43 \%$ of commuters using paratransit are work-based trip, $31 \%$ of commuters are of personal business trip, $20 \%$ of commuters are home based trip and $6 \%$ of commuters are related to recreation trip.

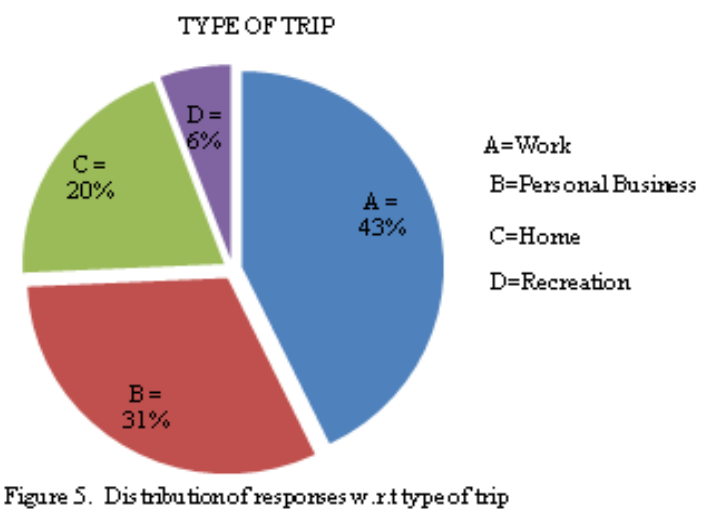

5. From the figure6, 34\% of commuters using paratransit has good satisfaction, $60 \%$ of commuters has average satisfaction and $6 \%$ of commuters has poor satisfaction.

\section{SATISFACTIOH LEVEL}

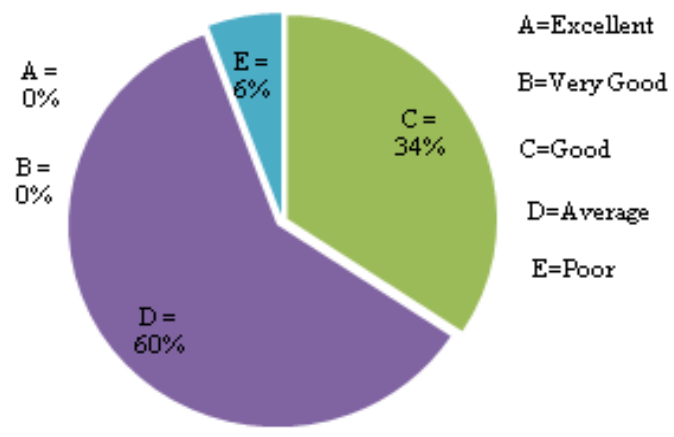

Figure 6. Dis tribution of resporses w.r.ts atisfaction level

6. From the figure7, $20 \%$ of commuters using paratransit has less than $7 \mathrm{~km}$ trip length, $40 \%$ of commuters has 7 to $10 \mathrm{~km}$ trip length and $40 \%$ of commuters has greater than $10 \mathrm{~km}$ trip length.

\section{TRAVEL LENGTH}

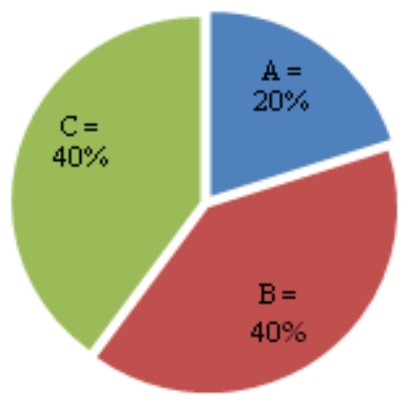

A - $-\varepsilon=7 \mathrm{~km}$ $\mathrm{B}-(7-10) \mathrm{km}$ C- $>10 \mathrm{~km}$

Figure 7. Dis tribution of responses w.r.t travel length
DISCUSSIONS:

\section{AT SDM CHOURAHA}

Houseunit Type:

$\mathrm{A}=0 \% ; \mathrm{B}=40 \% ; \mathrm{C}=60 \%$;

Household Income Group:

$\mathrm{A}=0 \% ; \mathrm{B}=34 \% ; \mathrm{C}=37 \% ; \mathrm{D}=29 \%$;

Occupation:

$\mathrm{A}=11 \% ; \mathrm{B}=37 \% ; \mathrm{C}=46 \% ; \mathrm{D}=0 \% ; \mathrm{E}=0 \% ; \mathrm{F}=6 \%$

Satisfaction Level:

$\mathrm{A}=0 \% ; \mathrm{B}=0 \% ; \mathrm{C}=34 \% ; \mathrm{D}=60 \% ; \mathrm{E}=6 \%$;

Type Of Trip:

$\mathrm{A}=43 \% ; \mathrm{B}=31 \% ; \mathrm{C}=20 \% ; \mathrm{D}=6 \%$

Travel Length:

$\mathrm{A}=20 \% ; \mathrm{B}=40 \% ; \mathrm{C}=40 \%$;

At SDM Chouraha, based on the above observations and analysis it indicates that maximum numbers of commuters are not having personal vehicles. Therefore, most of the people in this location are choosing paratransit as their mode of transport.

\section{ROAD WAY JUNCTION}

1. From the figure8, 54\% of commuters using paratransit are having self contained flat and $46 \%$ of commuters has rental houses. HOUSE UHIT TYPE

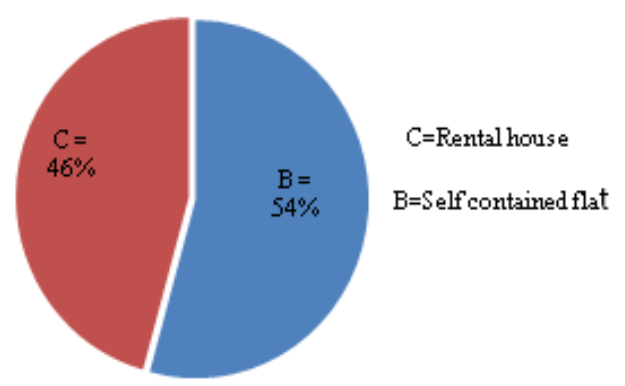

Figure 8. Dis trbutionof resporses $w . r$. thouse urit type

2. From the figure9, $48 \%$ of commuters using paratransit has no vehicle, $46 \%$ of commuters having 1 vehicle and $6 \%$ of commuters are having more than one vehicle.

\section{NUMBER OF 2-WHEELERS}

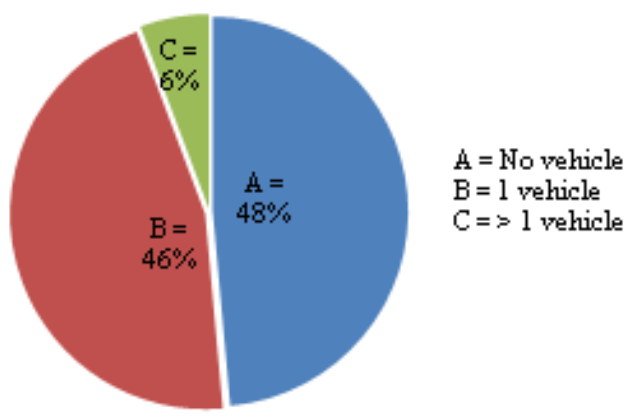

Figure 9. Dis tribution of respones w.r.t noof 2-wheeles 
3. From the figure 10, $14 \%$ of commuters using paratransit are of Rs.3000-Rs.5000 income group, $34 \%$ of commuters are of Rs.5000-Rs. 10000 income group and $52 \%$ of commuters are having income greater than Rs. 10000.

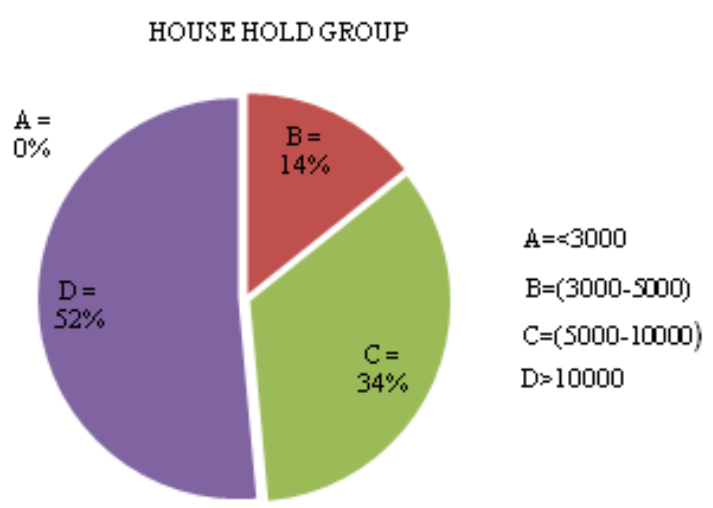

Figure 10. Dis trbution of responses w.r.t hase hold group

4. From the figure $11,3 \%$ of commuters using paratransit are students, $37 \%$ of commuters are industrial workers and $60 \%$ of commuters are businessmen.

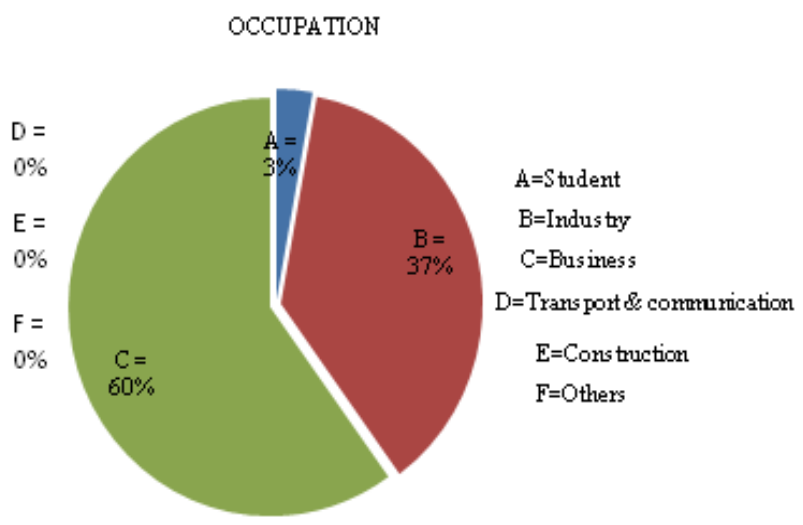

Figurell . Dis tnbution of responses w.r.toccupation

5. From the figure12, 29\% of commuters using paratransit are work based trip, $54 \%$ of commuters are personal business trip, $11 \%$ of commuters are shopping, $3 \%$ of commuters are educational trip and $3 \%$ of commuters has recreation trip.

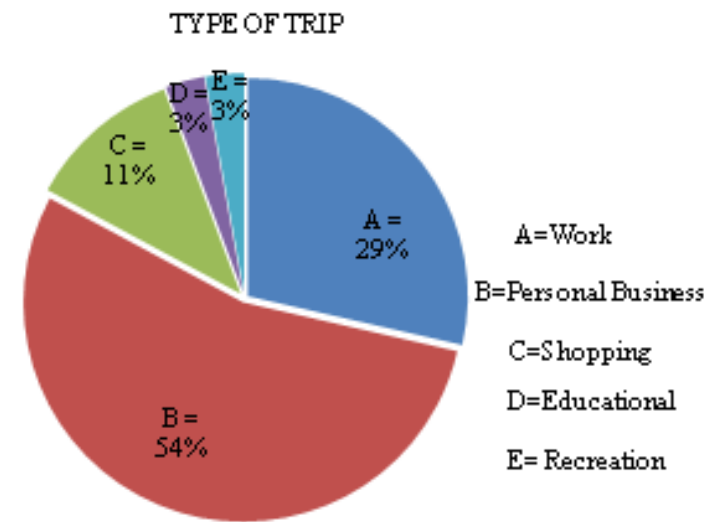

Figure 12. Dis thbution of responses w.r.t type of trip
6. From the figure $13,40 \%$ of commuters using paratransit are having good satisfaction level, $46 \%$ of commuters are of average satisfaction level and $14 \%$ of commuters are with poor satisfaction level.

\section{SATISFACTION LEVEL}

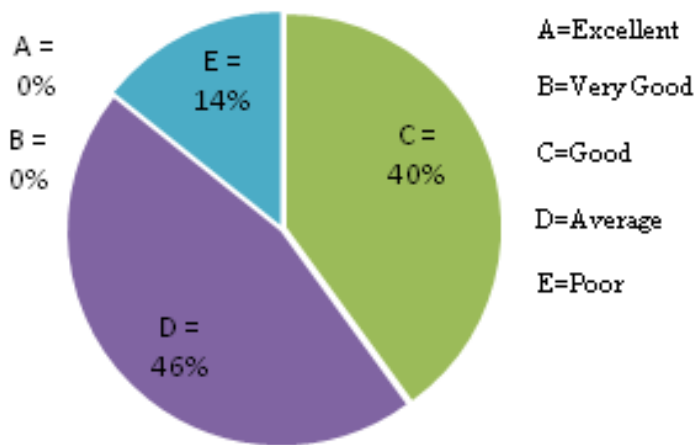

Figure 13. Dis tribution of responses w.r.t satisfation level

7. From the figure $14,26 \%$ of commuters using paratransit are less than $5 \mathrm{~km}$ travel length, $34 \%$ of commuters are $5-10 \mathrm{~km}$ travel length and $40 \%$ of commuters are greater than $10 \mathrm{~km}$ travel length.

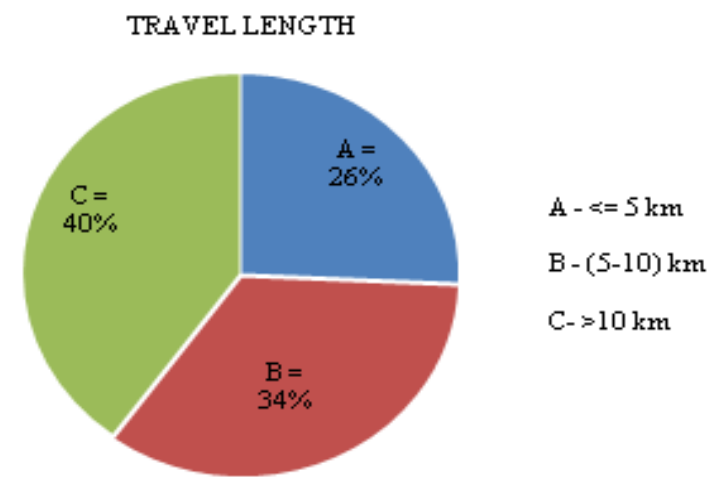

Figure 14. Dis thbution of responses w.r.t travel length

DISCUSSIONS:

\section{AT ROADWAY JUNCTION}

House unit Type:

$\mathrm{A}=0 \% ; \mathrm{B}=54 \% ; \mathrm{C}=46 \%$;

Household Income Group:

$\mathrm{A}=0 \% ; \mathrm{B}=14 \% ; \mathrm{C}=34 \% ; \mathrm{D}=52 \%$;

Occupation:

$\mathrm{A}=3 \% ; \mathrm{B}=37 \% ; \mathrm{C}=60 \% ; \mathrm{D}=0 \% ; \mathrm{E}=0 \% ; \mathrm{F}=0 \%$

Satisfaction Level:

$\mathrm{A}=0 \% ; \mathrm{B}=0 \% ; \mathrm{C}=40 \% ; \mathrm{D}=46 \% ; \mathrm{E}=14 \%$;

Type of Trip:

$\mathrm{A}=29 \% ; \mathrm{B}=54 \% ; \mathrm{C}=11 \% ; \mathrm{D}=3 \% ; \mathrm{E}=3 \%$;

Travel Length:

$\mathrm{A}=26 \% ; \mathrm{B}=34 \% ; \mathrm{C}=40 \%$;

Number of 2-Wheelers:

$\mathrm{A}=48 \% ; \mathrm{B}=46 \% ; \mathrm{C}=6 \%$; 
At Road Ways junction, based on the above observations and analysis, it indicates that maximum number of commuters are having self contained flat and occupation as business. But most of the commuters in this location are using paratransit as their mode for business trips regularly.

\section{MALAKPURI CHUNGI}

1. From the figure 15, $27 \%$ of commuters using paratransit has no vehicle, $60 \%$ of commuters has 1 vehicle and $13 \%$ of commuters are having more than one vehicle NUMBER OF 2-WHEELERS

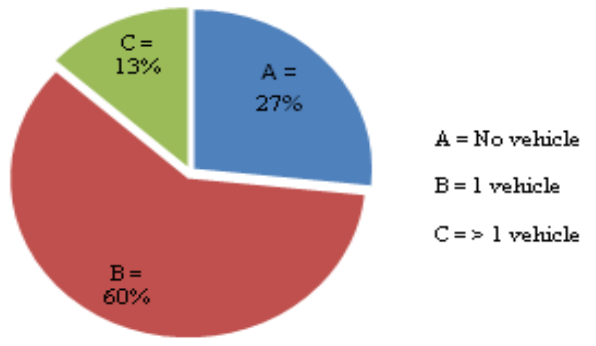

Figure 15. Dis trbution of responses w.r.t no. of 2 wheeles

3. From the figure16, 3\% of commuters using paratransit are luxurious, $50 \%$ of commuters are self contained flat and $47 \%$ are rental houses.

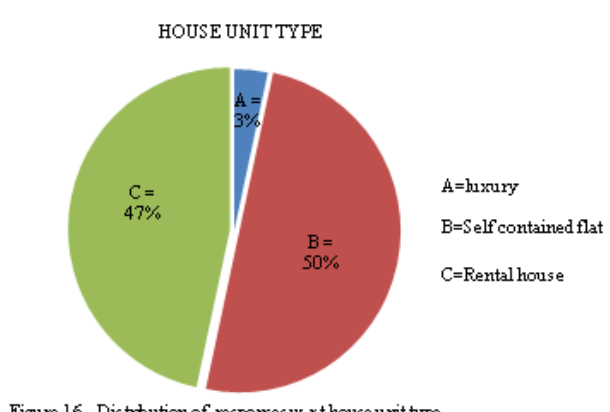

3. From figure17, $13 \%$ of commuters using paratransit are having monthly household income between Rs.3000-Rs.5000, 34\% of commuters are between Rs.5000-Rs. 10000 and $53 \%$ of commuters are having monthly household income greater than Rs. 10000 .

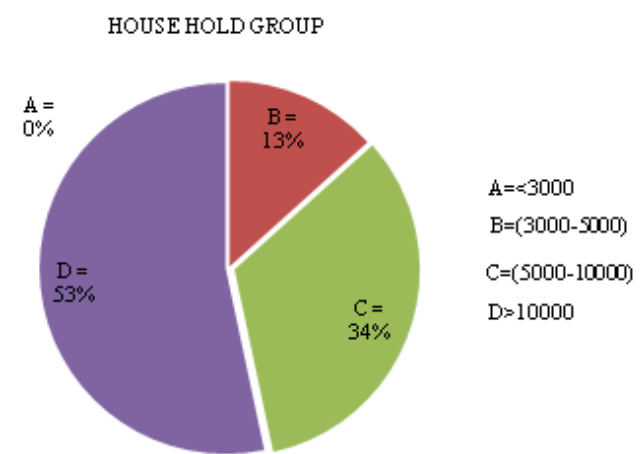

Figure 17. Dis trbution of responses w.r.t hase hold group
4. From the figure $18,20 \%$ of commuters using paratransit are students, $27 \%$ of commuters are industry based, $50 \%$ of commuters are businessmen, and $3 \%$ of commuters are construction based.

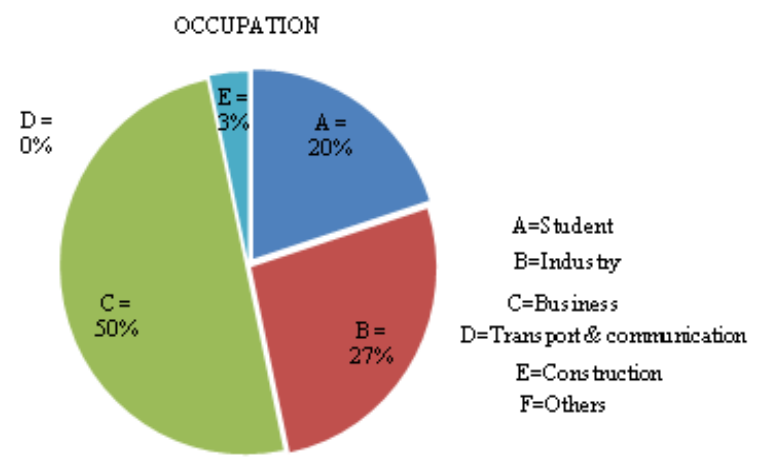

Figure 18. Dis trbution of res ponses w.r.t occupation

6. From the figure19, $44 \%$ of commuters using paratransit are workbased trip, 23\% of commuters are personal business trip, 3\% of commuters are shopping, $17 \%$ of commuters are educational trip and $13 \%$ of commuters has recreation trip

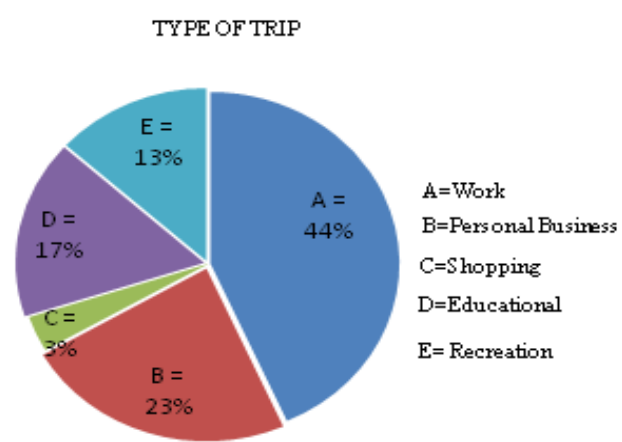

Figure 19. Dis trbution of res ponses w.r.t type of trip

6. From the figure 20, 57\% of commuters using paratransit has good satisfaction level, $30 \%$ of commuters has average satisfaction level and $13 \%$ of commuters has poor satisfaction level. SATISFACTION LEVEL

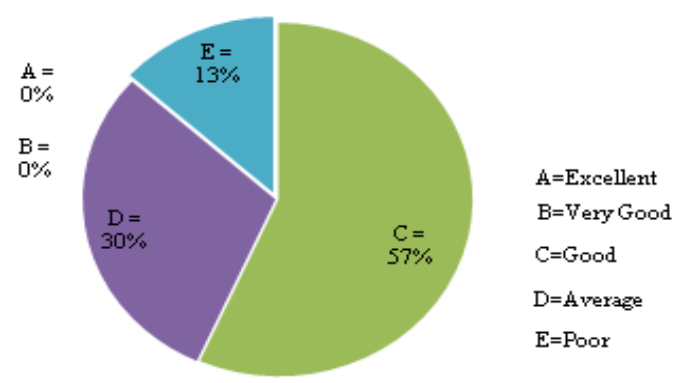

Figure 20. Dis trbution of res ponses w.r.t satisfactionlevel 
7. From the figure $21,43 \%$ of commuters using paratransit has less than $5 \mathrm{~km}$ trip length and $57 \%$ of commuters has greater than $5 \mathrm{~km}$ trip length.

\section{TRAVEL LENGTH}

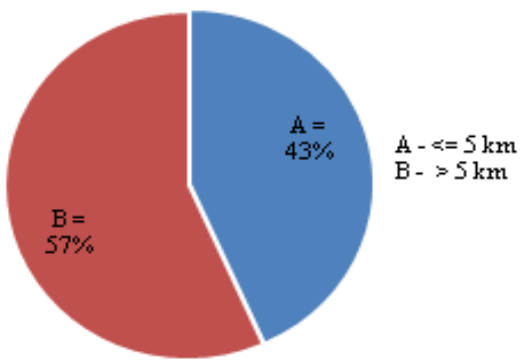

Figure 21. Dis thbution of responses w.r.t travel length

8. From the figure 22, $7 \%$ of commuters using paratransit has one or more than one car and $93 \%$ of commuters has no car.

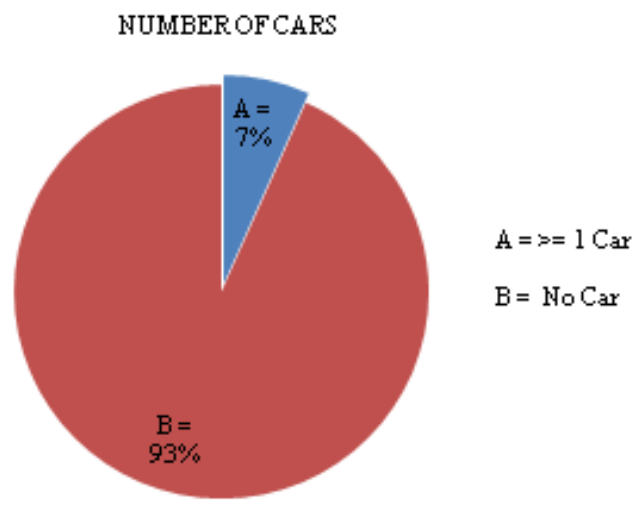

Figure 22. Dis trbution of res ponses w.r.t no of car

\section{DISCUSSIONS: AT MALAKPURI CHUNGI}

House unit Type:

$\mathrm{A}=3 \% ; \mathrm{B}=50 \% ; \mathrm{C}=47 \%$;

Household Income Group:

$\mathrm{A}=0 \% ; \mathrm{B}=13 \% ; \mathrm{C}=34 \% ; \mathrm{D}=53 \%$;

Occupation:

$\mathrm{A}=20 \% ; \mathrm{B}=27 \% ; \mathrm{C}=50 \% ; \mathrm{D}=0 \% ; \mathrm{E}=3 \% ; \mathrm{F}=0 \%$

Satisfaction Level:

$\mathrm{A}=0 \% ; \mathrm{B}=0 \% ; \mathrm{C}=57 \% ; \mathrm{D}=30 \% ; \mathrm{E}=13 \%$;

Type of Trip:

$\mathrm{A}=44 \% ; \mathrm{B}=23 \% ; \mathrm{C}=3 \% ; \mathrm{D}=17 \% ; \mathrm{E}=13 \%$;

Travel Length:

$\mathrm{A}=43 \% ; \mathrm{B}=57 \%$;

No of 2-Wheelers: $A=27 \% ; B=60 \% ; C=13 \%$;

No of Cars: $A=7 \% ; B=93 \%$;

Based on the above observations and analysis at Malakpur Chungi, the maximum numbers of commuters are having atleast one vehicle but many students are using paratransit as their mode in this area.

\section{CONCLUSIONS}

i. At SDM Junction, the maximum number of users are rental houses with monthly house hold income group of (Rs.5000- Rs.10000), the users are mostly working in industries nearby which is regarded as their occupation, type of trip generated is work based only ,travel length is greater than $7 \mathrm{kms}$ and their satisfaction level is average.

ii. At Road ways Junction, the maximum number of users are having own houses with house hold income group of greater than Rs.10000, the occupation of the users are mostly business, type of trip generated is personal business, travel length is greater than $5 \mathrm{~km}$ and their satisfaction level is average.

At Malakpuri chungi Junction, the maximum number of users are of rental houses with house hold income group of greater than Rs.10000, the occupation of the users are mostly working, type of trip generated is work based trip and educational trips, and their satisfaction level is average.

\section{REFERENCES}

[1] Antonio M, "A route set construction algorithm for the transit network design problem", Vol.36, 2009, pp 24402449.

[2] Cathey F. W. et al (2003), "A prescription for transit arrival/departure prediction using automatic vehicle location data", TR part C, pp 241-264.

[3] Diwakar gupta,etal (2010), "Improving the efficiency of demand-responsive para transit services", TRR No 44, pp 201-217.

[4] Juan carlos. M (2010), "On the development of public transit in large cities", TRR vol. 29, pp 379-386.

[5] Kadiyali L. R. (2009). "Traffic Engineering and transportation planning", Khanna publishers pp 651-657.

[6] Kunle. A (1987), "Para-transit modes in Nigeria" TRR No. 44, pp 339-347.

[7] Mulley C.etal (2009), "Flexible transport services for Research in transportation economics ", RTE 25, pp 39-45.

[8] Phuong Nguyen-hoang. etal (2010), "What is para transit worth" for Transportation Research, TRR No 44, pp 841853

[9] Peter. T etal (2006), "Vernacular cabs : Jitneys and gypsies in cities", TRR No. 44, pp 457-468.

[10] Rastogi. R etal (2003), "Defining Transit accessibility with environmental inputs", TR Part D, pp 383-396. 